\title{
КОРРЕКТИРОВКА СТРАТЕГИЙ БАНКОВ В УСЛОВИЯХ СНИЖЕНИЯ РЕНТАБЕЛЬНОСТИ РОССИЙСКОГО БАНКОВСКОГО СЕКТОРА
}

\begin{abstract}
АНнотАция. Современный финансовый кризис вызвал острую необходимость перемен в области управления банковской деятельностью. В последние десять лет эффективность деятельности банков снижается, что отражается в падении таких показателей, как рентабельность активов и рентабельность капитала банковского сектора. Основными причинами снижения прибыли банков является необоснованный рост расходов, связанный с недостаточно адекватным управлением банковскими рисками. Именно эти причины заставляют Банк России проводить более жесткую политику в части регулирования и надзора за деятельностью банков, основная цель которой - вывод с рынка банков с неудовлетворительным финансовым состоянием. Вопросам повышения эффективности банковской деятельности в экономической литературе не уделено должного внимания. В последние годы сильно изменилась внешняя среда, в которой функционируют банки. Им необходимо быстро адаптироваться к меняющимся макро- и микроэкономическим условиям, повышая качество работы, менеджмента и технологий обслуживания. В статье содержится анализ причин снижения рентабельности российских банков, а также попытка выделить ключевые меры, связанные с изменением стратегических задач и призванные решить данные проблемы.
\end{abstract}

КЛЮЧЕВЫЕ сЛОВА. Кредитная организация; банки; рентабельность; прибыль; чистый доход; устойчивость; стратегия.

ИНФОРМАЦИЯ О СТАТЬЕ. Дата поступления 15 апреля 2016 г.; дата принятия к печати 13 мая 2016 г.; дата онлайн-размещения 1 июля 2016 г.

Yu. B. Bubnova

Baikal State University,

Irkutsk, Russian Federation

\section{CORRECTING STRATEGIES OF BANKS IN TERMS OF DECLINING PROFITABILITY OF THE RUSSIAN BANKING SECTOR}

\begin{abstract}
Modern financial crisis has created a sharp necessity for changes in management of banking activities. In the last ten years, the efficiency of banks has been decreasing, which is reflected in the drop in such indicators as return on assets and return on equity of the banking sector. The main reasons for decreasing profits of banks is unjustified increase in expenses associated with inefficient management of banking risks. These reasons as often as not make the Bank of Russia pursue more tough policy of regulating and supervising of banking activities, whose main goal is withdrawing banks with unsatisfactory financial condition from the market. The issues of improving efficiency of banking activities are not paid due attention in the economic literature. Over recent years the external environment in which banks operate has changed greatly. They need to quickly adapt to changing macro- and microeconomic conditions while enhancing the quality of work, management, and service technologies. The article contains an analysis of the reasons for decreasing profitability of Russian banks, as well as an attempt to identify key measures related to changes in strategic objectives in order to solve these problems.

KEYWORDS. Credit institution; banks; profitability; profit; net income; sustainability; strategy.

ARTICLE INFO. Received April 15, 2016; accepted May 13, 2016; available online July 1, 2016.
\end{abstract}

(C) Ю. Б. Бубнова, 2016

\section{Baikal Research Journal}


В последние несколько лет идет активный отзыв лицензий у кредитных организаций. С момента прихода Э. Набиуллиной на пост главы Банка России (2013-2016) количество действующих кредитных организаций сократилось на четверть: с 956 организаций до 718.

В рамках политики оздоровления и укрепления банковского сектора Банк России применяет риск-ориентированные подходы к осуществлению банковского надзора. Более консервативная оценка банковских рисков предполагает повышение оперативности реагирования со стороны подразделений дистанционного надзора Банка России на негативное развитие ситуации в отдельных банках. Это должно привести к прекращению маскировки низкого качества активов представлением недостоверной отчетности, выведения недобросовестными собственниками из кредитных организаций качественных активов в другие подконтрольные им же организации. С рынка банковских услуг выводятся банки с неудовлетворительным финансовым состоянием.

Тем не менее, в последние два года на фоне сокращения численности кредитных организаций, преимущественно с неудовлетворительным финансовым состоянием, происходит снижение ключевых финансовых показателей деятельности кредитных организаций: рентабельности активов и капитала.

Коэффициент рентабельности капитала, получивший в мировой практике название ROE, показывает эффективность работы банка с позиции интересов его акционеров, характеризуя производительность вложенных ими средств. В последние годы средняя норма рентабельности капитала в банках США составляет 13-16 \%, французских - $5 \%$, британских $-20 \%$. Коэффициент прибыльности активов предназначен для проведения анализа эффективности операций банка и управления им в целом. Его допустимые значения — от 0,005 до 0,050 [1, с. 103].

Снижение данных показателей наблюдается на протяжении последних десяти лет по всем группам банков (табл.). По сокращению данных показателей Россия опережает даже страны БРИК. Так, рентабельность капитала сократилась за пять лет на $41 \%$, тогда как в среднем по другим странам БРИК падение составило 29 \% [2, с. 7].

\section{Диналика рентабельности активов и капитала банков, \%}

\begin{tabular}{|c|c|c|c|c|c|c|}
\hline $\begin{array}{c}\text { Показа- } \\
\text { тель }\end{array}$ & $\begin{array}{c}\text { Год (по со- } \\
\text { стоянию } \\
\text { на } 1 \text { января) }\end{array}$ & $\begin{array}{l}\text { Банки, кон- } \\
\text { тролируемые } \\
\text { государством }\end{array}$ & $\begin{array}{c}\text { Банки с участи- } \\
\text { ем иностранно- } \\
\text { го капитала }\end{array}$ & $\begin{array}{c}\text { Крупные } \\
\text { частные } \\
\text { банки } \\
\end{array}$ & $\begin{array}{l}\text { Средние и малые } \\
\text { банки Москов- } \\
\text { ского региона }\end{array}$ & $\begin{array}{c}\text { Региональные } \\
\text { малые и сред- } \\
\text { ние банки }\end{array}$ \\
\hline \multirow{9}{*}{$\begin{array}{l}\text { Рента- } \\
\text { бель- } \\
\text { ность } \\
\text { акти- } \\
\text { вов }\end{array}$} & 2007 & 3,5 & 3,0 & 3,3 & 2,1 & 2,9 \\
\hline & 2008 & 3,2 & 3,1 & 2,9 & 2,4 & 3,0 \\
\hline & 2009 & 2,2 & 1,8 & 1,3 & 1,5 & 2,1 \\
\hline & 2010 & 0,7 & 1,1 & 0,4 & 1,2 & 1,1 \\
\hline & 2011 & 2,4 & 2,1 & 1,1 & 1,4 & 1,5 \\
\hline & 2012 & 2,8 & 2,4 & 1,7 & 1,5 & 1,7 \\
\hline & 2013 & 2,5 & 2,5 & 1,9 & 1,5 & 1,7 \\
\hline & 2014 & 2,0 & 2,2 & 1,6 & 1,9 & 1,6 \\
\hline & 2015 & 1,2 & 1,6 & 0,1 & 1,1 & 1,6 \\
\hline \multirow{9}{*}{\begin{tabular}{|l} 
Рента- \\
бель- \\
ность \\
капита- \\
ла
\end{tabular}} & 2007 & 33,1 & 23,5 & 26,3 & 9,8 & 17,9 \\
\hline & 2008 & 22,8 & 25,0 & 24,2 & 11,9 & 18,7 \\
\hline & 2009 & 15,7 & 14,6 & 10,6 & 6,9 & 13,1 \\
\hline & 2010 & 4,3 & 8,3 & 3,2 & 5,2 & 6,2 \\
\hline & 2011 & 14,8 & 14,5 & 8,4 & 6,7 & 9,8 \\
\hline & 2012 & 20,6 & 17,4 & 14,2 & 8,0 & 10,4 \\
\hline & 2013 & 20,1 & 18,8 & 16,0 & 8,5 & 10,7 \\
\hline & 2014 & 17,2 & 15,1 & 12,9 & 10,2 & 10,2 \\
\hline & 2015 & 10,2 & 11,1 & 1,2 & 6,2 & 9,6 \\
\hline
\end{tabular}

Составлено по данным отчетов о развитии банковского сектора и банковского надзора за 20062014 гг. URL : http://cbr.ru/publ/?PrtId=nadzor.

\section{Baikal Research Journal}


Так, у банков, контролируемых государством, рентабельность активов снизилась практически в три раза, в то время как у других групп банков - в два раза. Рекордно низкий уровень рентабельности активов показали крупные частные банки в 2014 г. $0,1 \%$. Уровень рентабельности активов выровнялся. Аналогичным образом менялся уровень рентабельности капитала. Необходимо отметить, что самые низкие показатели рентабельности активов и капитала наблюдаются на протяжении всего периода у средних и малых банков Московского региона. Неслучайно, что более половины отозванных лицензий Банком России приходится на банки данного региона.

По мнению заместителя председателя Банка России В. А. Поздышева, негативные изменения в финансовом состоянии российских банков в 2014 г. были вызваны реализацией системного риска, обусловленного следующими основными факторами:

- падение курса национальной валюты по отношению к резервным валютам, вызвавшее снижение уровня достаточности капитала у банков, имеющих существенные активы в инвалюте при сбалансированной открытой валютой позиции;

- падение цен на российском фондовом рынке, приведшее к убыткам банков вследствие отрицательной переоценки портфелей ценных бумаг;

- отток вкладов населения в рублях и инвалюте;

- ухудшение кредитного качества заемщиков и рост резервов на возможные потери по ссудам [3, с. 5].

В целях компенсации влияния указанных факторов и стабилизации финансового положения банковского сектора Банк России предпринял ряд мер, в том числе регулятивных. Но, несмотря на ужесточающиеся требования к достаточности и размеру капитала банка, положительную динамику активов и капитала кредитных организаций, данные показатели все-равно продолжали снижаться (рис. 1). Причиной такой динамики стало падение прибыли банков, а также рост доли убыточных банков.

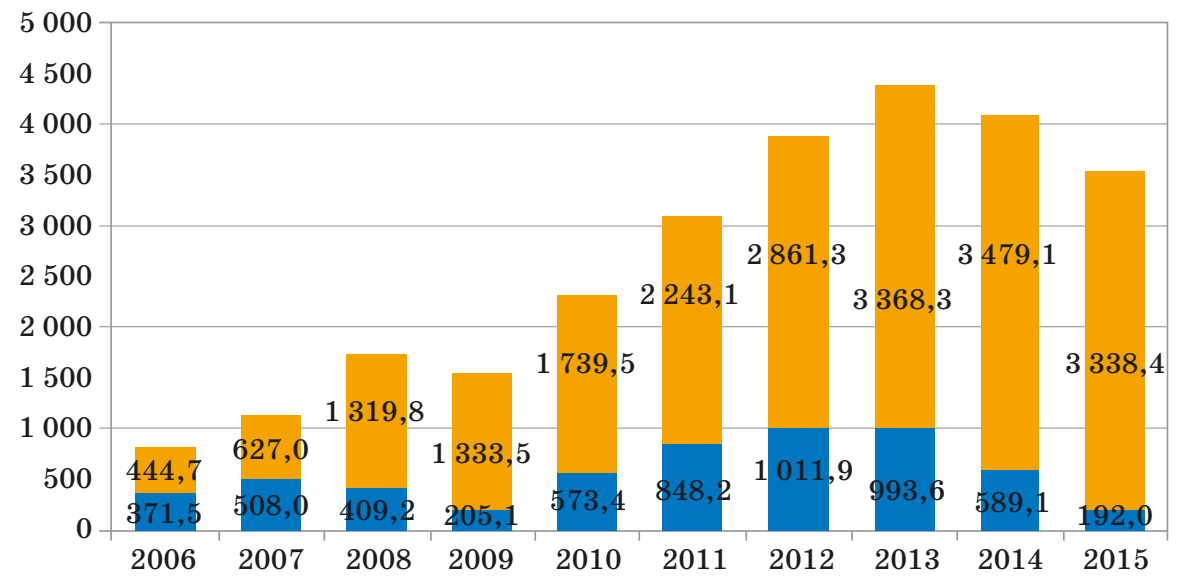

Pис. 1. Диналика прибыли отчетного года и прибыли с учетом доходов прошлых лет кредитных организаций в 2006-2015 г2., \%

Составлено по: URL : http://cbr.ru/publ/?PrtId=nadzor;

URL:http://www.cbr.ru/analytics/bank_system/obs_1604.pdf

Максимальный размер годовой прибыли был в 2012 г., превысив 1 трлн р. В 2014 г. уровень прибыли был чуть выше уровня 2010 г., а в 2015 г. - ниже, чем в 2009 г. По мнению экспертов Департамента экспертно-аналитических работ АНО «Аналитический центр при Правительстве Российской Федерации», за послед-

\section{Baikal Research Journal}


ние месяцы банковский сектор начал устойчиво генерировать прибыль. Например, по итогам января-октября 2015 г. банки получили совокупную прибыль (до уплаты налогов) в размере 193 млрд р., из которых только на октябрь пришлось 64,6 млрд р., что стало максимальным уровнем за 13 месяцев. Однако учитывая, что положительный финансовый результат стал возможен благодаря деятельности только нескольких крупных банков, утверждать о стабильности текущей тенденции пока рано. В частности, положительный вклад внес ПАО «Сбербанк России», которое продолжило наращивать прибыль, по-прежнему играя определяющую роль в прибыльности всей системы. Без учета его прибыли совокупные убытки банковского сектора за 10 месяцев 2015 г. составили 18,2 млрд р. [4, с. 41].

Необходимо отметить, что сокращение прибыли кредитных организаций идет на фоне роста доли убыточных кредитных организаций, а, следовательно, и размера убытка, полученного такими кредитными организациями [5, с. 45]. Если в период мирового финансового кризиса 2008-2009 гг. убыточные кредитные организации составляли десятую часть действующих, то в 2014 г. - шестую часть $(15,1 \%)$, а по итогам 2015 г. - четверть всех действующих кредитных организаций (рис. 2).

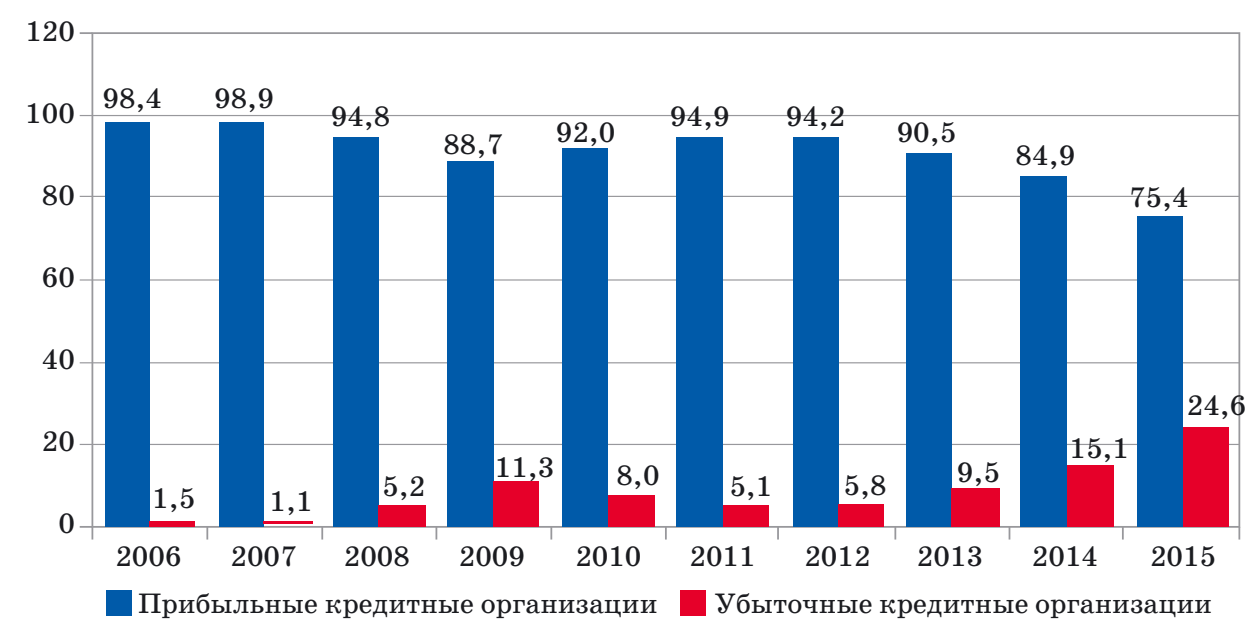

Рис. 2. Соотношение прибыльных и убыточных кредитных организаций в 2006-2015 г2., \%

Составлено по: URL : http://cbr.ru/publ/?PrtId=nadzor; URL: http://www.cbr.ru/analytics/bank_system/obs_1604.pdf

Размер прибыли банка зависит от уровня его чистых доходов и операционных расходов (расходов, связанных с обеспечением деятельности кредитных организаций, в том числе налогов).

Основным драйвером роста чистых доходов банков на протяжении длительного периода были чистые процентные доходы (получаемые в результате осуществления депозитно-кредитной и инвестиционной деятельности), набирали обороты и становились значимыми чистые комиссионные доходы. В последние несколько лет сокращение чистых процентных доходов было основной причиной падения прибыли банковского сектора. На снижение доходности кредитной и инвестиционной деятельности банков повлияло как замедление темпов кредитования, так и рост рискованности этой деятельности, что отразилось на увеличении резервов на возможные потери, которые банки формируют в обязательном порядке. Пока кредитование росло, доходы от вновь выданных ссуд перекрывали расходы, связанные как с уплатой процентов по полученным средствам (депозитам, кредитам, выпущенным

\section{Baikal Research Journal}


долговым обязательствам), так и с формированием резервов, недополучением процентов по просроченным кредитам. У многих банков по итогам 2014-2015 гг. изменение резервов на возможные потери стало причиной снижения чистых процентных доходов или даже их отрицательной величины.

Существенными расходами для банков были затраты, связанные с обеспечением деятельности кредитной организации, сокращение которых шло гораздо меньшими темпами, чем снижение чистых доходов. $K$ сожалению, данные о структуре чистого дохода банковского сектора начиная с 2008 г. отсутствуют, зато мы можем проследить влияние определенных факторов на формирование прибыли по банковскому сектору (рис. 3).

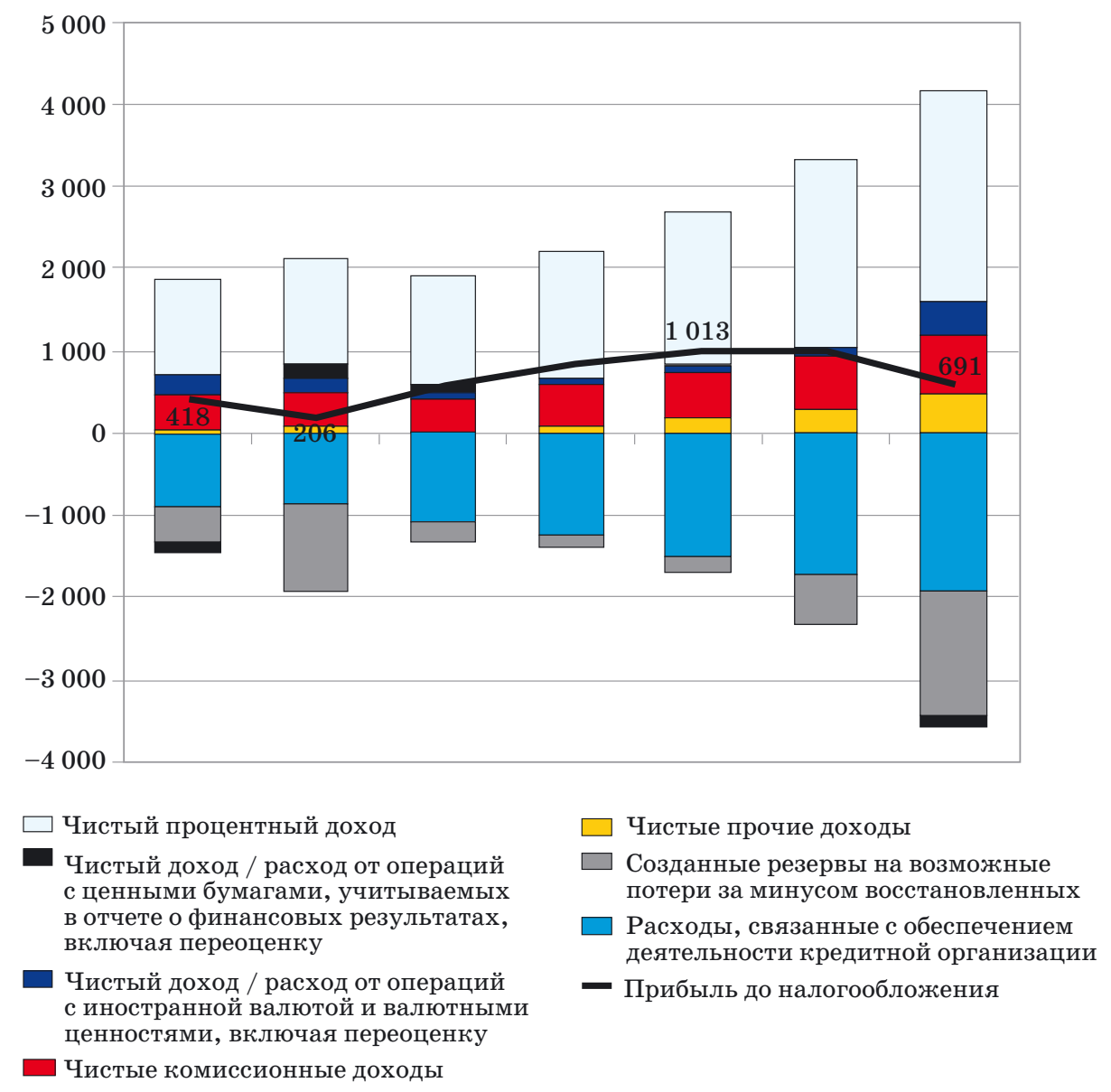

Рис. 3. Факторы форлирования прибыли по банковсколу сектору в 2008-2014 22.

Источник:URL : http://www.cbr.ru/publ/archive/root_get_blob.aspx?doc_id=9878

На протяжении всего периода основными факторами роста прибыли были чистый процентный и комиссионный доход, а основными факторами снижения - расходы, связанные с обеспечением деятельности, и созданные резервы на возможные потери (за минусом восстановленных). Причем в 2014 г. последний фактор значительно вырос. Это связано, прежде всего, с высоким уровнем просроченной задолженности по кредитам, выданным физическим лицам, вследствие высокого уровня в портфелях банков необеспеченных ссуд.

\section{Baikal Research Journal}


Основной проблемой в банковском секторе продолжает оставаться стремительно ухудшающаяся ситуация с розничными банками (доля просроченной задолженности в октябре 2015 г. достигла 8,1 \%, что на $0,6 \%$ выше пиковых значений 2010 г.). Продолжающийся рост проблемной задолженности усиливает давление на и без того ослабленный капитал розничных банков. В результате это приводит к ухудшению их финансовой устойчивости, что отражается в оценках международных рейтинговых агентств, в случае, например, с банками «Русский стандарт» и «Восточный экспресс», рейтинг которых находится уже на минимально возможных низких уровнях «Саа2» и «Саa1» соответственно, что является преддефолтными уровнями [4, с. 41].

В этой ситуации виноваты не только заемщики, но и сами банки, которые достаточно формально подходили к оценке кредитоспособности клиентов, а следовательно, недооценивали риски. Именно неумелое управление рисками привело многие банки к потери своей устойчивости, и, как следствие, к отзыву лицензий.

Необходимо остановиться и на расходах, связанных с обеспечением деятельности кредитной организации, которые начиная с 2010 г. росли, а за пять лет они практически удвоились. Это при замедлении объемов кредитования и увеличении рисков кредитной деятельности.

По данным Ассоциации российских банков, соотношение административно-управленческих расходов к активам за пятилетний период в банковской системе России выросло на $125 \%$, тогда как в Германии $-8 \%$, в Китае $-5 \%$, в США $-1 \%$, в Индии $-23 \%$ [2, с. 7].

В этой связи банкам предстоит задуматься над экономией, а такие мероприятия возможны только за счет совершенствования организационной структуры банка, а также пересмотра внутрибанковского устройства. Необходимость оптимизации выявляется посредством рассмотрения и анализа структуры банка, определения его слабых мест, а также перспективных направлений. Особенно остро такой вопрос стоит перед крупными многофилиальными банками, которые с 2004 г. начали масштабную экспансию в регионы путем открытия большого количества внутренних структурных подразделений. Экономия должна коснуться и расходов на содержание персонала, которые составляют половину, а в некоторых банках 60-70 \%, и расходов, связанных с обеспечением деятельности. Этому должны способствовать предпринятые Банком России меры, среди которых введение в действие инструкции «О порядке оценки системы оплаты труда в кредитной организации и порядке направления в кредитную организацию предписания об устранении нарушения в ее системе оплаты труда» от 17 июня 2014 г. № 154-И. Эта инструкция даст Банку России возможность требовать от кредитных организаций устранения недостатков в их системах оплаты труда в случае выявления их несоответствия принимаемым рискам, а также характеру и масштабам деятельности кредитной организации. Первая оценка будет проводиться Банком России по состоянию на 1 октября 2015 г. В связи с началом оценки систем оплаты труда в кредитных организациях предполагается также внести соответствующие изменения в порядок расчета показателя риска материального стимулирования (ПУ7) и включения его в расчет показателя качества управления банка в рамках указания Банка России «Об оценке экономического положения банков» от 30 апреля 2008 г. № 2005-У [3, с. 6].

Еще одним фактором снижения прибыли стал рост процентных расходов. Резкие изменения курса иностранных валют (доллара и евро) обусловили значительные структурные изменения балансовых показателей, а скачки рыночных процентных ставок увеличивали стоимость фондирования кредитных организаций. В условиях возросшей стоимости фондирования агрессивная политика ряда банков на рынке вкладов населения при отсутствии эффективной системы управления рисками и при низком качестве активов обернулась снижением процентной маржи и убытка-

\section{Baikal Research Journal}

электронный научный журнал Байкальского государственного университета 
ми. Это в итоге отразилось на резком сокращении совокупной прибыли кредитных организаций.

На фоне высокого уровня инфляции процентные ставки как по кредитам, так и по депозитам банков в ближайшие годы снижаться не будут, для банков это означает рост процентных расходов, связанных с обслуживанием депозитов, и снижение возможностей для размещения кредитов из-за их недоступности вследствие высоких процентных ставок как для физических, так и для юридических лиц. Кроме того, растут кредитные риски банков. С ростом инфляции все больше доходов населения идет на потребление, а с учетом его «закредитованности» будет расти и кредитная нагрузка. Так, по оценкам экспертов, она может доходить до 40-50 \% дохода заемщика. В США, где относительный уровень задолженности населения в 4-5 раз выше, нагрузка по обслуживанию и погашению кредитов на располагаемые доходы даже ниже, чем в России, и не превысила в 2013 г. 10 \% [6, с. 11].

Из-за ухудшения условий для функционирования бизнеса качество обслуживания кредитов этой категории клиентов также может ухудшиться, что приведет к росту просроченной задолженности и как следствие - к недополучению процентных доходов и росту расходов, связанных с формирование резервов.

Прогнозы неутешительны! Начиная с 2013 г. прирост привлеченных средств начал догонять прирост объема выданных кредитов, а в 2015 г. уже вдвое превысил его (рис. 4). Это, в свою очередь, приведет к более быстрому росту расходов по выплате процентов по сравнению с менее быстрым ростом объема процентных доходов по предоставленным кредитам, что еще больше сократит процентную маржу банков и уменьшит прибыль.

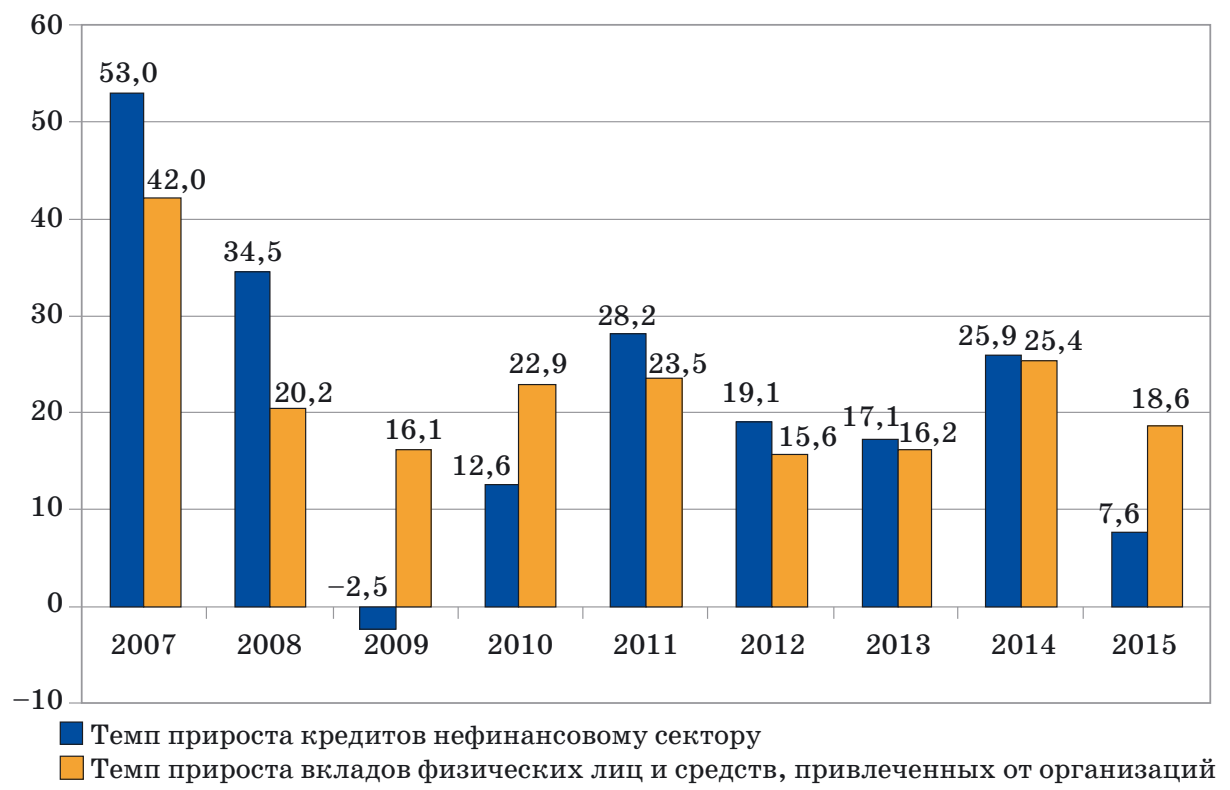

Рис. 4. Соотношение темпов роста кредитов нефинансовому сектору и средств, привлеченных от физических лии и организаций, в 2007-2015 г2., \%

Составлено по: URL : http://cbr.ru/publ/?PrtId=nadzor; URL:http://www.cbr.ru/analytics/bank_system/obs_1604.pdf

В части сегмента кредитования физических лиц в 2015 г. мы наблюдали падение, наиболее существенное за последние годы: на 5,7 \% сократился кредитный портфель физическим лицам. Следует обратить внимание на то, что существенно

\section{Baikal Research Journal}


для этого рынка. Первые пять крупнейших российских банков не сократили объемы кредитования физических лиц, в основном за счет развития ипотеки и за счет того, что их базовые продукты необеспеченных ссуд были ориентированы на так называемые «зарплатные» проекты. В целом падение кредитного портфеля неравномерно, и очень многое зависит от качества банковских продуктов [7, с. 4].

Учитывая вероятность дальнейшего снижения реальных доходов населения и его закредитованность, рассчитывать на восстановление розничного кредитования в ближайшее время пока не приходится. В этой связи банкам, как коммерческим структурам, необходимо серьезно задуматься над эффективностью своей деятельности.

Растущий быстрыми темпами объем кредитного портфеля (особенно необеспеченных кредитов) в прошлые годы для многих банков представлялся лишь как инструмент зарабатывания текущей сверхприбыли. Банки не задумывались о росте рисков, им казался оправданным рост организационных расходов, связанных с содержанием увеличивающегося числа внутренних структурных подразделений. Лишь те банки, которые вели достаточно взвешенную политику в области оценки рисков и грамотную процентную политику, смогли сохранить свою устойчивость. Именно региональные банки, по нашему мнению, сумели достойно пройти непростой период мирового финансового кризиса 2008-2009 гг. с минимальными потерями рентабельности активов и капитала (по сравнению с банками других групп), сохранить достигнутый уровень и в последние годы, непростые для финансового рынка России. Банки, имеющие хорошо проработанную стратегию своего поведения, учитывающие всевозможные внешние и внутренние факторы, в том числе геополитические, смогли в этой ситуации сохранить рентабельность своего бизнеса.

В настоящее время банки должны выбрать ту стратегию, которая будет соответствовать их внутреннему ресурсному потенциалу. В том случае, если в результате реализации стратегии выполнение задач будет затруднено, то необходимо внести корректировку. Особое внимание банку нужно уделять внешним факторам, как экономическим, так и политическим. Для этого они должны составлять собственные прогнозы состояния внешней среды (базовый, оптимистичный и пессимистичный) и, в зависимости от этого, разрабатывать различные варианты поведения при реализации стратегии.

Кредитные организации, выигравшие в конкурентной борьбе, повысившие качество менеджмента, расширившие спектр востребованных качественных банковских услуг, увеличат свою клиентскую базу и, как следствие, будут получать большую прибыль [8, с. 208].

Сложившаяся ситуация в экономике и банковской сфере требует новой парадигмы развития взаимоотношений между кредитными организациями, их клиентами и регуляторами. На смену подозрениям и обвинениям в адрес друг друга должен прийти подход, заключающийся в совместном решении возникающих проблем во имя общего блага и в интересах каждого.

Для этого есть все предпосылки. Так, динамично растет доступность интернет-технологий для граждан и организаций, что позволяет предоставлять все больший процент финансовых услуг с использованием дистанционных каналов. Но самое главное: растет доверие к банкам со стороны не только их клиентов, но и общества в целом [9, с. 11].

Повышение качества работы банков с меньшими издержками и с большей эффективностью сегодня важно как никогда. На протяжении последних лет качественный уровень работы, менеджмент, технологии в банковской сфере хотя и несколько продвинулись вперед, но еще значительно отстают от международных стандартов. Для дальнейшего развития банковского сектора необходим переход к новому этапу, особенность которого состоит в качественном улучшении работы.

\section{Baikal Research Journal}

электронный научный журнал Байкальского государственного университета 
Под влиянием рынка произошли значительные структурные изменения в банковском секторе. На данный момент в стране существует свыше 700 кредитных организаций. Это в 3-4 раза меньше, чем в начале $90-\mathrm{x}$ гг. XX в. Теперь жизнь требует тщательно проанализировать ситуацию и продумать планомерную систему укрепления и развития банков. Главная задача на современном этапе - выйти на мировой уровень развития банковской системы. Ее решение предполагает развертывание работы по следующим направлениям:

- определение новых стратегических задач, стоящих перед банковским сектором, и его места в ходе экономического развития;

- формирование модели управления банковской системой снизу доверху;

- определение внутренней организации процессного подхода в банках [10, с. 18].

Достижение успеха в современном банковском бизнесе зависит от наличия у банка стратегии развития и эффективных инструментов ее внедрения. Стратегия необходима на любом этапе экономического развития: и в периоды роста, и в периоды стабильности, и тем более в кризисный период. Это связано с тем, что в стратегии просчитываются все основные риски, все возможные сценарии развития макросреды и действия банка на рынке, что повышает предсказуемость ситуации и соответственно обеспечивает прозрачность принятия управленческих решений $[11$, с. 308].

Всем банкам, независимо от их специализации и масштабов деятельности, необходимо серьезно задуматься над выработкой грамотной стратегии, направленной на стабильное долгосрочное функционирование, а не на получение сиюминутной прибыли. Банкам, которые долгое время придерживались достаточно агрессивной модели своего поведения, необходимо менять стратегию своего развития, регулировать ее, совершенствовать внутренние структуры управления, технологию обслуживания клиентов.

\section{Список использованной литературы}

1. Татаринова Л. В. Методические подходы к оценке финансовой устойчивости коммерческого банка : монография / Л. В. Татаринова. - Иркутск : Изд-во БГУЭП, 2013. - 132 с.

2. Тосунян Г. А. О перспективах банковской системы России: взгляд банковского сообщества / Г. А. Тосунян // Деньги и кредит. $-2014 .-$ № 5. - С. 5-7.

3. Поздышев В. А. Развитие банковского регулирования в России в 2015 году / В. А. Поздышев // Деньги и кредит. - 2015. - № 1. - С. 5-8.

4. Наметкин Д. Н. Об основных проблемах финансовой стабильности / Д. Н. Наметкин, Н. Ю. Сафина // Деньги и кредит. - 2016. - № 1. - С. 41-44.

5. Бубнова Ю. Б. Влияние новой политики Банка России на институциональные характеристики российской банковской системы / Ю. Б. Бубнова // Современный этап развития российской экономики : межвуз. сб. науч. тр. - Иркутск : Иркут. гос. ун-т путей сообщений, 2014. - Вып. 4. - С. 41-48.

6. Ведев А. Актуальные проблемы развития банковской системы в Российской Федерации / А. Ведев, С. Синельников-Мурылев, М. Хромов // Экономическая политика. 2014. - № 2. - C. 7-24.

7. Сухов М. И. Современная банковская система России: некоторые актуальные аспекты / М. И. Сухов // Деньги и кредит. - 2016. - № 1. - С. 3-6.

8. Последствия вступления России во Всемирную торговую организацию для региональной экономики / А. П. Киреенко, Д. Ю. Федотов, Л. В. Санина [и др.]. - Иркутск : Изд-во БГУЭП, 2013. - $252 \mathrm{c}$.

9. Тосунян $\Gamma$. А. К вопросу об укреплении банковского сектора в текущей экономической ситуации / Г. А. Тосунян // Деньги и кредит. - 2016. - № 3. - С. 7-11.

10. Милюков А. И. Некоторые актуальные проблемы повышения качества работы банков / А. И. Милюков // Деньги и кредит. - 2015. - № 12. - С. 18-20.

11. Тысячникова Н. А. Стратегическое планирование в коммерческих банках: концепция, организация, методология : научное издание / Н. А. Тысячникова, Ю. Н. Юденков. М. : Кнорус : Центр исслед. платеж. систем и расчетов, 2013. - 312 с.

\section{Baikal Research Journal}

электронный научный журнал Байкальского государственного университета 
12. Лаврушин О. И. Эффективность банковской деятельности: методология, критерии, показатели, процедуры / О. И. Лаврушин, Т. Н. Ветрова // Банковское дело. — 2015. № 5. - C. 38-42.

\section{References}

1. Tatarinova L. V. Metodicheskie podkhody k otsenke finansovoi ustoichivosti kommercheskogo banka [Methodical approaches to assessment of commercial banks' financial sustainability]. Irkutsk, Baikal State University of Economics and Law Publ., 2013. 132 p.

2. Tosunyan G. A. On prospects of the Russian banking system: a banking community view. Den'gi $i$ kredit $=$ Money and Credit, 2014, no. 5, pp. 5-7. (In Russian).

3. Pozdyshev V. A. Banking regulation development in Russia in 2015. Den'gi $i$ kre-dit $=$ Money and Credit, 2015, no. 1, pp. 5-8. (In Russian).

4. Nametkin D. N., Safina N. Yu. On major problems of financial stability. Den'gi $i$ kredit $=$ Money and Credit, 2016, no. 1, pp. 41-44. (In Russian).

5. Bubnova Yu. B. Influence of new policy of Bank of Russia on institutional characteristics of the Russian banking system. Sovremennyi etap razvitiya ekonomiki [Current Stage of Economic Development]. Irkutsk, Baikal State University of Economics and Law Publ., 2014, iss. 4, pp. 41-48. (In Russian).

6. Vedev A., Sinelnikov-Murylev C., Khromov M. Topical problems of developing banking system in the Russian Federation. Ekonomicheskaya politika = Economic Policy, 2014, no. 2, pp. 7-24. (In Russian).

7. Sukhov M. I. Contemporary Russian banking system: Topical issues. Den'gi $i$ kredit $=$ Money and Credit, 2016, no. 1, pp. 3-6. (In Russian).

8. Kireenko A. P., Fedotov D. Yu., Sanina L. V. et al. Posledstviya vstupleniya Rossii vo Vsemirnuyu torgovuyu organizatsiyu dlya regional'noi ekonomiki [The Consequences of Russia's Entry Into The World Trade Organization for The Regional Economy]. Irkutsk, Baikal State University of Economics and Law Publ., 2013. $252 \mathrm{p}$.

9. Tosunyan G. A. On enhancing the banking sector in the current economic environment. Den'gi $i$ kredit $=$ Money and Credit, 2016, no. 3, pp. 7-11. (In Russian).

10. Milyukov A. I. Certain topical issues pertaining to enhancing the quality of bank's operations. Den'gi i kredit = Money and Credit, 2015, no. 12, pp. 18-20. (In Russian).

11. Tysyachnikova N. A. Yudenkov Yu. N. Strategicheskoe planirovanie v kommercheskikh bankakh: kontseptsiya, organizatsiya, metodologiya [Strategic planning in commercial banks: concept, organization, methodology]. Moscow, Knorus Publ., Centre for Investigating Payment systems and Calculations Publ., 2013. $312 \mathrm{p}$.

12. Lavrushin O. I., Vetrova T. N. Efficiency of banking activity: methodology, criteria, procedures. Bankovskoe delo = Banking, 2015, no. 5, pp. 38-42. (In Russian).

\section{Информация об авторе}

Бубнова Юлия Борисовна - кандидат экономических наук, доцент, кафедра банковского дела и ценных бумаг, Байкальский государственный университет, 664003, г. Иркутск, ул. Ленина, 11, e-mail: 23bal@mail.ru.

\section{Author}

Yulia B. Bubnova - PhD in Economics, Associate Professor, Chair of Banking and Securities, Baikal State University, 11 Lenin St., 664003, Irkutsk, Russian Federation; e-mail: 23bal@mail.ru.

\section{Библиографическое описание статьи}

Бубнова Ю. Б. Корректировка стратегий банков в условиях снижения рентабельности российского банковского сектора / Ю. Б. Бубнова / Baikal Research Journal. — 2016. — T. 7, № 4. - DOI : 10.17150/2411-6262.2016.7(4).3.

\section{Reference to article}

Bubnova Yu. B. Correcting strategies of banks in terms of declining profitability of the Russian banking sector. Baikal Research Journal, 2016, vol. 7, no. 4. DOI : 10.17150/24116262.2016.7(4).3. (In Russian).

\section{Baikal Research Journal}

